\title{
Oral manifestation and its management in postmenopausal women: an integrated review
}

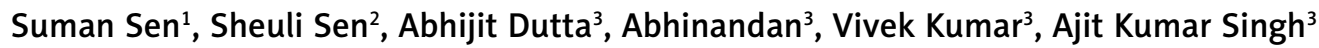 \\ ${ }^{1}$ Department of Oral Medicine and Radiology, Haldia Institute of Dental Sciences and Research, Haldia, West Bengal, India \\ ${ }^{2}$ Department of Pediatric Nursing, Amity College of Nursing, Gurugram, India \\ ${ }^{3}$ Department of Oral Pathology and Microbiology, Awadh Dental College and Hospital, Jamshedpur, India
}

\begin{abstract}
Postmenopause is a phase of life which leads physical and emotional instability from multiple health related issues. Oral health in this stage of life is also compromised. Oral health has an impact on general wellbeing of the individual as oral cavity is commonly act as a mirror to general health. Menopause is phase in a woman's life when menstrual cycles cease by reduced secretion of the ovarian hormones, such as estrogen and progesterone. This review article has emphasized on the diverse oral presentations of peri- and postmenopausal phase of women's life. Practicing dental surgeons and general physician should be aware of the possible association of postmenopause and its various oral signs and symptoms in this midlife phase of women. It also focuses on its symptomatic management of various oral health issues. This article explains diverse oral conditions in detailed and their management. Stress causing anxiety and depression among this midlife phase of women can lead to alteration in immunity which can again lead to various oral conditions, like lichen planus, apthous ulcer that can cause burning sensation in oral mucosa and alter the food habit. By dealing with all this diverse condition, practicing oral physician can help to reduce and manage oral manifestation of postmenopausal phase of life.
\end{abstract}

Key words: postmenopause, oral manifestations, osteoporosis, periodontitis, psychological change.

\section{Introduction}

There are numerous challenges faced by postmenopausal women in their life. Oral health is one of the important thing which often gets ignored. The impact of multiple oral sign and symptoms can range from physical to psychological stress. A practicing dental surgeon has to be his own sociologist and psychologist to understand that he is dealing with a patient, who not only has specific symptoms in the mouth but is changing and evolving human beings with complex inter relationship of biological, medical, psychological and social problems in the background. Menopause is a physiological process typically occurring in the fifth decade of life in women. Menopause refers to the permanent cessation of menstruation owing to loss of the ovarian follicular activity [1]. A diagnosis of natural menopause is made retrospectively following 12 months of amenorrhea with no pathologic association [2].

The two major female hormones are estrogen and progesterone. Apart from the reproductive tissue estrogen effect was found to have receptors in bone, endothelial cells, ligaments and gingival tissues, reductive effect on the keratinized gingival tissue which will lead to reduced effectiveness of the oral epithelium as a barrier [3-5].

The fact that oral health has a direct effect on overall physical and mental health of a person which has been established by a large number of studies and researches worldwide. Numerous symptoms associated with menopause vary from person to person. Oral health is an integral part of general health. oral manifestations is caused mainly due to initial decrease in estrogen, which directly leads to a vasomotor disturbance this in turn causes an increase in neurosis and it is the change in psychological status which results in the various oral symptoms [6]. The following are the oral manifestations noted at menopause.

\section{Burning mouth syndrome}

Burning mouth syndrome (BMS), also known as glossodynia or stomatodynia, mainly affects women in the fourth or fifth decade of life. The disorder shows a clear female predominance [7]. BMS is described as a burning sensation affecting different areas of the oral cavity. It is often bilateral, and is characterized by the 
absence of pathological findings. The accompanying symptoms may include dry mouth sensation or alterations in taste sensation [8-10]. The most commonly used local anesthetic agent, lidocaine. use of tricyclic antidepressants such as amitriptyline, desipramine, imipramine, clomipramine and nortriptyline (starting dose of $5-10 \mathrm{mg} /$ day and gradually increases to $50 \mathrm{mg} /$ day) are useful in treating BMS. Topical application of capsaicin $(0.025 \%$ cream) has been used in BMS as a desensitizing agent [11].

\section{Xerostomia}

Xerostomia is dryness of mouth caused by decreased salivary secretion. Saliva plays a major role in self-cleaning of oral cavity. It acts as natural lubricating and immunomodulation agent which inhibit various fungal diseases and dental caries. Estrogen hormone receptors have been detected in the oral mucosa [12-16]. Menopause leads to decrease in salivary flow rates and alteration in levels of electrolytes in the saliva $[16,17]$. Certain studies conducted showed that salivary flow decreases in menopausal women with increase in salivary IgA and total proteins [3]. Hormone replacement along with alendronate and calcium improved saliva flow rate in women with oral symptoms [18]. Through clinical examination like silometery it is possible to check the viscosity and flow of saliva. Systemic sialogogues like pilocarpine, cevimeline and citrus lozenges are advised [19]. Patients should be advised to brush their teeth using fluoride toothpaste diligently, avoid sweet food to prevent dental caries.

\section{Gingiva and periodontium}

Gingiva is the mucosal tissue that lies over the mandible and maxilla inside the mouth while periodontium is the specialized tissues that both surround and support the teeth. Postmenopausal women present with periodontal disease more frequently and more severe [18]. Postmenopause can lead to changes in inflammatory mediators, vascular permeability and growth and differentiation of fibroblasts. There are estrogen receptors in osteoblasts and fibroblasts of periodontal tissues, respond depending on levels of hormones in different stages of reproductive life and thus affect the health of the periodontium [19-21]. Moreover, decrease in female hormones suppresses the intestinal absorption of calcium, which in turn increases the serum parathyroid hormone and, as a result, the bone resorption is increases. Good oral hygiene maintaining tips from dentist like proper brushing eliminates plaque from the teeth surfaces, flossing removes food particles and plaque from interdental region and under the gum line. Antibacterial mouth rinses can reduce bacteria that cause plaque.

\section{Mucosal changes}

Oral mucosa resembles vaginal mucosa in its histology as well as its response to estrogens. Sex hormone receptors have been detected in the oral mucosa [12-14]. Menopausal gingivostomatitis where the gingival surfaces appears pale dry and shiny with erythematous appearance and occasional bleeding [22]. Apart from this, oral mucosal disorders include candidiasis, pemphigus vulgaris, benign mucosal pemphigoid. Moreover, stress causing anxiety and depression which is mainly causes of lichen planus and oral ulcerations is also noted in postmenopausal women. Oral lichen planus is commonly noted at the end of fourth decade and fifth decade of life with female predilection [23]. Hormonal therapy with estradiol in patients with identifiable estrogen receptors at the oral epithelial level may be beneficial in certain oral conditions $[3,22]$.

\section{Neurological disorders}

Trigeminal neuralgia is characterized by severe unilateral, lancinating, "electric-shock" like sharp pain usually in the middle and lower third of the face. This condition is noted in postmenopausal women occasionally mostly due to compression of superior cerebellar artery on ophthalmic, maxillary and mandibular branches of trigeminal nerve [24]. Alzheimer's disease and atypical facial pain/neuralgia sometimes also noted postmenopausal women [25]. Carbamazepine, oxcarbazepine, lamotrigine, gabapentin, pregabalin and baclofen are few drug of choice which are given in various doses to reduce trigeminal neuralgia [26].

\section{Eating disorders}

Stress sometimes causes eating disorders. Due to reduced salivary secretion causing xerostomia caused alter in taste sensation. This also acts as a contributing factor for eating disorder. Self-induced vomiting and resultant regurgitation of gastric contents. The stomach acid can cause erosion, increased incidence of caries and overall discoloration of the teeth due to persistent vomiting. Smooth erosion of enamel, enlarged parotid glands, trauma to oral mucous membrane and pharynx resulting from use of fingers, combs, and pen to induce vomiting, angular cheilitis, dehydration, and erythema may be observed in menopausal women suffering from eating disorders [27].

\section{Osteoporosis}

Estrogen deficiency leads to upregulation of immune cells (macrophages and monocytes) and osteoclasts, which are responsible for a greater production of bone-resorbing cytokines [28-30]. Systemic osteoporo- 
sis leading to generalized bone loss may make the jaws susceptible to advanced alveolar bone loss, decreased bone mineral density. This in turn can lead to early tooth loss making the women edentulous. Osteoporosis is known as a "silent disease," because the loss of bone mass does not cause symptoms [31, 32]. A detail radiographs, periodontal probing is indicated to check for bone reabsorption and its effect on dentition. The prevalence of osteoporotic fractures increases from $4 \%$ in women at age 50 to $52 \%$ of women age 70 years [33].

Menopause hormone therapy is recommended for women who are at risk of osteoporotic fractures and who are younger than 60 years old, while for those who are older than 60 years, menopause hormone therapy is not recommended if it is intended only for the prevention of osteoporotic fractures [34] calcium and vitamin D supplements also helps to induce the bone mineral density.

\section{Conclusions}

Menopause is a physiological phase that gives adaptive change at systemic and oral level. The practicing dental surgeon must remember that he is treating a human being with psychological and emotional needs. Menopause has been proven that it highly affects oral and dental structures which need to be managed. The dental treatment of such patients involves a series of particularities that should be taken into account, like the use of salivary secretion stimulators or saliva substitutes in cases of hyposialosis. Proper protection and prevention with good control of bacterial plaque, contributes to reduce the risk of many infections within the oral cavity. Oral health specialists and gynecologists should be aware of the problems associated with menopause and need to provide these women complete health package consisting of oral health care as an integral part.

\section{Disclosure}

The authors report no conflict of interest.

\section{References}

1. Bruce D, Rymer J. Symptoms of the menopause. Best Pract Res Obstet Gynaecol 2009; 23: 25-32.

2. Nelson HD. Menopause. Lancet 2008; 371: 760-770.

3. Portillo GM. Oral manifestations and dental treatment in menopause. Med Oral 2002; 7: 31-35.

4. Mariotti A. Sex steroid hormones and cell dynamics in the periodontium. Crit Rev Oral Biol Med 1994; 5: 27-53.

5. Friedlander $\mathrm{AH}$. The physiology, medical management and oral implications of menopause. J Am Dental Assoc 2002; 33: 73-81.

6. Ferguson M, Carter J, Boyle P, et al. Oral complaints related to climacteric symptoms in oophorectomized women. J Royal Soc Med 1981; 74: 492-498.

7. López-Jornet P, Camacho-Alonso F, Andujar-Mateos P, et al. Burning mouth syndrome: An update. Med Oral Patol Oral Cir Bucal 2010; 15: 562-568.
8. Perno M. Burning mouth syndrome. J Dent Hyg 2001; 75: 245-252.

9. Woda A, Dao T, Gremeau-Richard C. Steroid dysregulation and stomatodynia (burning mouth syndrome). J Orofac Pain 2009; 23: 202-210.

10. Abetz LM, Savage NW. Burning mouth syndrome and psychological disorders. Aust Dent J 2009; 54: 84-93.

11. Aravindhan R, Vidyalakshmi S, Kumar MS, et al. Burning mouth syndrome: A review on its diagnostic and therapeutic approach. J Pharm Bioallied Sci 2014 Jul; 6 (Suppl 1): S21-S25.

12. Lopez BC, Perez MG, Soriano YJ. Dental considerations in pregnancy and menopause. J Clin Exp Dent 2011; 3: e135-144.

13. Thompson IO, van der Bijl P, van Wyk CW, van Eyk AD. A comparative light-microscopic, electron-microscopic and chemical study of human vaginal and buccal epithelium. Arch Oral Biol 2001; 46: 1091-1098.

14. Leimola-Virtanen R, Pennanen R, Syrjänen K, Syrjänen S. Estrogen response in buccal mucosa - A cytological and immunohistological assay. Maturitas 1997; 27: 41-45.

15. Leimola-Virtanen R, Salo T, Toikkanen S, et al. Expression of estrogen receptor (ER) in oral mucosa and salivary glands. Maturitas 2000; 36: 131-137.

16. Välimaa H, Savolainen S, Soukka T, et al. Estrogen receptor-beta is the predominant estrogen receptor subtype in human oral epithelium and salivary glands. J Endocrinol 2004; 180: 55-62.

17. Tarkkila L, Linna M, Tiitinen A, et al. Oral symptoms at menopause - The role of hormone replacement therapy. Oral Surg Oral Med Oral Pathol Oral Radiol Endod 2001; 92: 276-280.

18. Sewón L, Laine M, Karjalainen S, et al. The effect of hormone replacement therapy on salivary calcium concentrations in menopausal women. Arch Oral Biol 2000; 45: 201-206.

19. Villa A, Connell CL, Abati S. Diagnosis and management of xerostomia and hyposalivation. Ther Clin Risk Manag 2015; 11: 45-51.

20. Yalcin F, Gurgan S, Gul G. Oral health in postmenopausal Turkish women. Oral Health Prev Dent 2006; 4: 227-233.

21. Mascarenhas P, Gapski R, Al-Shammari K, Wang HL. Influence of sex hormones on the periodontium. J Clin Periodontol 2003; 30: 671-681.

22. Amar S, Chung KM. Influence of hormonal variation on the periodontium in women. Periodontol 2000 1994; 6: 79-87.

23. Scardina GA, Messina P. Oral microcirculation in post-menopause: A possible correlation with periodontitis. Gerodontology 2012; 29: e1045-1051.

24. Paganini-Hill A. Hormone therapy and oral health. Menopause Manage 2007: 31-40.

25. Rajendran R, Sivapathasundaram B. Shafers Oral Pathology ( $6^{\text {th }}$ ed.). Elsevier India, India 2009: 800.

26. Obermann M. Treatment options in trigeminal neuralgia. Ther Adv Neurol Disord 2010; 3: 107-115.

27. Friedlander $\mathrm{AH}$. The physiology, medical management and oral implications of menopause. J Am Dent Assoc 2002; 133: 73-81.

28. Chiramana S, Ashok K. Examination, diagnosis and treatment planning for complete denture therapy: A review. J Orofac Sci 2010; 2: 29-35.

29. Steinberg BJ. Women's oral health issues. J California Dent Assoc 2000; 28: 663-667.

30. Pacifici R. Estrogen, cytokines and pathogenesis of postmenopausal osteoporosis. J Bone Miner Res 1996; 11: 1043-1051.

31. Pacifici R. Is there a causal role for IL-1 in postmenopausal bone loss? Calcif Tissue Int 1992; 50: 295-299.

32. Slavkin HC. Notes on a "silent disease". J Am Dent Assoc 1996; 127 : 801-803.

33. Riggs BL, Khosla S, Melton LJ III. A unitary model for involutional osteoporosis: estrogen deficiency causes both type I and type II osteoporosis in postmenopausal women and contributes to bone loss in aging men. J Bone Miner Res 1998; 13: 763-773.

34. The Chinese Menopause Society. Guidelines of hormone replacement therapy in menopause transition period and post menopause period (2009). Chin J Obstet Gynecol 2010; 45: 26-28. 